\title{
Synergistic Inhibition Effect Between Capsella bursa-pastoris Extracts and Iodide Ions for Q235 Mild Steel in 1 M HCI Solution
}

\author{
Qin $\mathrm{Hu}^{1}$, Yubing $\mathrm{Qiu}^{1}$, Guoan Zhang ${ }^{1}$ and Xingpeng Guo ${ }^{*}, 1,2$ \\ ${ }^{I}$ School of Chemistry and Chemical Engineering, Huazhong University of Science and Technology, Wuhan 430074, \\ China \\ ${ }^{2}$ Hubei Key Laboratory of Materials Chemistry and Service Failure, Wuhan 430074, China
}

\begin{abstract}
The inhibition effect of Capsella bursa-pastoris extracts (CBE) and its synergistic effect with KI (CBEK) for Q235 mild steel in $1 \mathrm{M} \mathrm{HCl}$ solution were studied by electrochemical measurements. Both CBE and CBEK can serve as eco-friendly, mixed-type inhibitors, and the inhibition efficiency increases with the concentration and temperature. The synergistic parameter $\left(S_{\mathrm{I}}\right)$ indicates a cooperative mechanism between the iodide anions and CBE molecules at lower temperature. The associated thermodynamic and kinetic data suggest the presence of CBEK on metal surface mainly through chemisorption at higher temperature. The adsorption processes follow Langmuir isotherm.
\end{abstract}

Keywords: Acid corrosion, electrochemical calculation, electrochemical techniques, mild steel, synergistic inhibition.

\section{INTRODUCTION}

It is well known that metal corrosion will result in the degradation and eventual failure of components and systems in the processing and manufacturing industries, which needs to be controlled or prevented by some methods, such as the barrier protection, galvanization, cathodic protection and inhibitors. Among these methods, using inhibitors, which can reduce the attack on metals by adding small amounts to the environment, is very popular. However, most of the synthetic inhibitors are expensive and highly toxic to the living systems. To avoid this situation, new class of natural inhibitors, which are extracted from nature plants, should be developed. Plant extracts, which can be obtained through simple extraction process, are generally low toxicity, ecofriendliness and inexpensive. Therefore, there has been a growing trend to try to find efficient and readily available inhibitors in natural products [1-6].

Generally, if two or more inhibitors are added to the same corrosive system, the inhibition effect may be much greater than the individual effect of each inhibitor, which can be called the synergistic effect [7]. Synergistic inhibition has been proven to be an effective means of improving the inhibitive efficiency, decreasing the amount of usage and diversifying the application of inhibitor. For example, halide ions either stimulate or inhibit the corrosion of metals, depending on the concentration. A high synergistic effect of iodide ions was reported through chemisorption on metal surface due to its larger size and ease of polarizability [8]. It is widely known that halide ions have synergistic effect with many organic compounds such as amines, amides, imidazolines or quaternary ammonium salts, which are

*Address correspondence to this author at the School of Chemistry and Chemical Engineering, Huazhong University of Science and Technology, Wuhan 430074, China; Tel.: +86-27-87543432; Fax: +86-27-87543632;

E-mail: guoxp@mail.hust.edu.cn strongly polar functional compounds and contain $\mathrm{P}, \mathrm{S}$, and $\mathrm{O}$ [9]. However, there are only a few studies on the synergistic effect of halide ions and plant extract.

Capsella bursa-pastoris, commonly known as shepherd's purse, is a wild plant, whose young leaves and roots are edible vegetables in China. Its chemical composition, including minerals, vitamin $\mathrm{A}$, ascorbic acid, proteins, linoleic acid and fatty acids, is considered to be beneficial to human health $[10,11]$. Besides the good nutritional value, Capsella bursa-pastoris presents important biological properties and medicinal properties, being used for antibleeding, anticancer [12], wound-healing and antioxidant agent [13], as well as for diabetes and fever treatment. The CBE contains mixtures of organic compounds in nature, which having nitrogen, sulfur, triple bonds and aromatic rings as effective inhibition function groups. In this study, the inhibitive effect of Capsella bursa-pastoris extract (CBE) and its synergistic inhibition effect with iodide ions (CBEK) on the corrosion of Q235 mild steel in $\mathrm{HCl}$ solution were studied by potentiodynamic polarization and electrochemical impedance spectroscopy (EIS) measurements. The inhibitive performance, adsorption behaviour, co-adsorption mechanism and synergistic effect were determined.

\section{MATERIALS AND METHODOLOGY}

\section{Preparation of the electrodes}

Q235 mild steel, with the chemical composition shown in Table 1, was machined into specimens with the dimensions of $1 \times 1 \times 0.6 \mathrm{~cm}$. A copper wire was soldered to each specimen to ensure electrical connection for electrochemical measurements. Then the specimens were mounted in PVC holder and embedded with epoxy resin with the exposed area of $1 \mathrm{~cm}^{2}$. The exposed surface of each specimen was ground with silicon carbide abrasive paper up to 1200 grits, and then 
Table 1. Chemical composition of Q235 mild steel.

\begin{tabular}{|c|c|c|c|c|c|c|c|c|c|}
\hline Element & $\mathbf{C}$ & $\mathbf{S i}$ & $\mathbf{M n}$ & $\mathbf{P}$ & $\mathbf{S}$ & $\mathbf{A l}$ & $\mathbf{N i}$ & $\mathbf{C r}$ & $\mathbf{C u}$ \\
\hline \hline Composition (wt \%) & 0.18 & 0.07 & 0.28 & 0.016 & 0.006 & -- & 0.01 & 0.02 & 0.05 \\
\hline
\end{tabular}

rinsed with double-distilled water, degreased with ethanol and acetone.

\section{Preparation of Solution}

The testing solution was $1 \mathrm{M} \mathrm{HCl}$, which was made up from analytical grade reagent and deionized water. The airdried aerial parts of Capsella bursa-pastoris was powdered in particle size lower than $0.3 \mathrm{~mm}$. The Capsella bursapastoris inhibitor was extracted by adding some powders to $50 \%$ ethanol $+50 \%$ water solution for $45 \mathrm{~min}$ under ultrasonic condition. These extract conditions were optimized by primordial orthogonal experiments. KI with various concentrations $(0.01-100 \mathrm{mM})$ was added to the solution to determine the inhibition efficiency of KI and the synergistic inhibition effect of Capsella bursa-pastoris and KI.

\section{Electrochemical Measurements}

Electrochemical measurements were carried out in a conventional three-electrode glass cell by using an electrochemical test system (CS350, China). A platinum foil was used as the counter electrode and a saturated calomel electrode (SCE), which was connected to the cell externally through a Luggin capillary tube, was served as reference electrode. All the potentials reported here were referred to this reference electrode. Polarization curves were measured from $-0.25 \mathrm{~V}$ to $0.25 \mathrm{~V} v s$ open circuit potential (OCP) with a constant sweep rate of $0.5 \mathrm{mV} / \mathrm{s}$. EIS was recorded over the frequency range of $100 \mathrm{kHz}$ to $10 \mathrm{mHz}$ at OCP when OCP reached steady status (within $\pm 1 \mathrm{mV} \mathrm{min}^{-1}$ ). From the calculated values of charge transfer resistance $\left(R_{\mathrm{ct}}\right)$ and corrosion current density $\left(i_{\text {corr }}\right)$, the inhibition efficiency $(\eta \%)$ was calculated from the following Eqs. $(1,2)$ :

$\eta \%=\left[\left(R_{\mathrm{ct}}^{\prime}-R_{\mathrm{ct}}\right) / R_{\mathrm{ct}}^{\prime}\right] \times 100$

$\eta \%=\left[\left(i_{\text {corr }}-i_{\text {corr }}^{\prime}\right) / i_{\text {corr }}\right] \times 100$

where $R_{\text {ct }}$ (uninhibited systems) and $R_{\text {ct }}$ (inhibited systems) are the charge transfer resistances calculated from EIS, while $i_{\text {corr }}$ (uninhibited systems) and $i_{\text {corr }}$ (inhibited systems) are the corrosion current densities calculated from Tafel polarization, respectively.

\section{RESULTS}

\section{Electrochemical Impedance Spectroscopy Measurements}

(EIS)

Fig. (1) shows the Nyquist plots of Q235 mild steel in $1 \mathrm{M} \mathrm{HCl}$ solution in absence and presence of $\mathrm{KI}$ and CBEK at $25^{\circ} \mathrm{C}$. It is seen that all the Nyquist plots are characterized by one depressed capacitive semicircle. This depressed capacitive semicircle should be attributed to the heterogeneity of electrode surface $[14,15]$. The diameter of the capacitive semicircle increases, i.e., an increase in the inhibition efficiency, with increasing KI concentration.
Furthermore, the diameter of the capacitive semicircle in coexistence of $\mathrm{KI}$ and $\mathrm{CBE}$ is much larger than that of each individual inhibitor, indicating the synergistic effect of $\mathrm{KI}$ and $\mathrm{CBE}$.
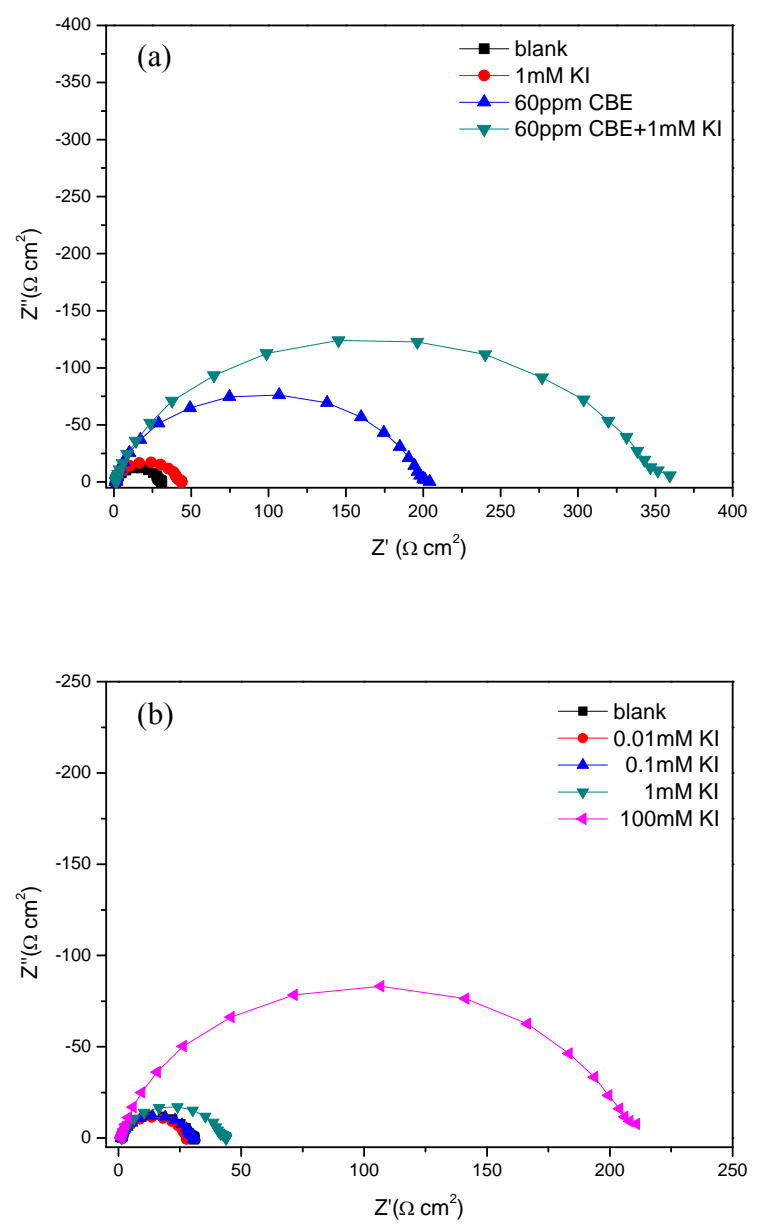

Fig. (1). Nyquist plots for Q235 mild steel in $1 \mathrm{M} \mathrm{HCl}$ solution (a) in the presence of $\mathrm{CBE}, \mathrm{KI}$ and $\mathrm{CBEK},(\mathbf{b})$ in the presence of different concentrations of $\mathrm{KI}$ at $25^{\circ} \mathrm{C}$.

To analyze and obtain the impedance parameters, an electrochemical equivalent circuit shown in Fig. (2) was used for fitting the EIS data, where $R_{\mathrm{S}}$ is solution resistance, $\mathrm{CPE}$ is constant phase element, $R_{c \mathrm{t}}$ is charge transfer resistance. The corresponding fitted values of impedance parameters are listed in Table 2 . It should be pointed out that the value of $C_{\mathrm{dl}}$ was obtained by converting the constant phase element parameter $\left(\mathrm{Y}_{0}\right)$ with following equation $[16,17]$ :

$C_{\mathrm{dl}}=\left(\mathrm{CPE}-\mathrm{T} \times R_{\mathrm{ct}}\right)^{1 / \mathrm{CPE}-\mathrm{P}} / R_{\mathrm{ct}}$

where CPE-T is the frequency independent admittance; CPE-P is the power of $\mathrm{Y}_{0}$. From Table 2, it is seen that the value of $R_{\mathrm{ct}}$ in coexistence of $\mathrm{KI}$ and $\mathrm{CBE}$ is larger than that 
Table 2. EIS fitted parameters for Q235 mild steel in $1 \mathrm{M} \mathrm{HCl}$ and in the presence of $\mathrm{CBE}$, $\mathrm{KI}$ or $\mathrm{CBEK}$ at $25^{\circ} \mathrm{C}$.

\begin{tabular}{|c|c|c|c|c|c|c|c|}
\hline $\begin{array}{c}c_{\mathrm{CBE}} \\
(\mathbf{p p m})\end{array}$ & $\begin{array}{c}c_{\mathrm{KI}} \\
(\mathrm{mM})\end{array}$ & $\begin{array}{c}R_{\mathrm{s}} \\
\left(\Omega \mathrm{cm}^{2}\right)\end{array}$ & $\begin{array}{c}R_{\mathrm{ct}} \\
\left(\Omega \mathrm{cm}^{2}\right)\end{array}$ & CPE-T & CPE-P & $\begin{array}{c}C_{\mathrm{dl}} \\
\left(\mu \mathrm{F} \mathrm{cc^{-2 }}\right)\end{array}$ & $\begin{array}{c}\eta \\
(\%)\end{array}$ \\
\hline 0 & 0 & 1.3 & 29.1 & 251.8 & 0.90 & 146.6 & -- \\
\hline 0 & 0.01 & 1.2 & 26.7 & 236.7 & 0.90 & 133.1 & -8.25 \\
\hline 0 & 0.1 & 1.2 & 29.1 & 234.5 & 0.90 & 130.5 & 0.10 \\
\hline 0 & 1 & 1.4 & 41.3 & 194.3 & 0.89 & 109.1 & 29.59 \\
\hline 0 & 100 & 1.1 & 211.4 & 103.3 & 0.88 & 60.2 & 86.23 \\
\hline 60 & 0 & 1.3 & 195.4 & 90.2 & 0.89 & 55.2 & 85.11 \\
\hline 60 & 0.01 & 1.1 & 236.7 & 101.5 & 0.87 & 58.1 & 87.71 \\
\hline 60 & 0.1 & 1.4 & 226.4 & 94.1 & 0.88 & 55.2 & 87.15 \\
\hline 60 & 1 & 1.3 & 344.0 & 82.2 & 0.86 & 45.7 & 91.54 \\
\hline
\end{tabular}

in the individual presence of $\mathrm{CBE}$ or $\mathrm{KI}$, which indicates the higher inhibition efficiency of CBEK compared to $\mathrm{CBE}$ or KI. Furthermore, the value of $R_{\mathrm{ct}}$ in the presence of $\mathrm{KI}$ is larger than that in the absence of KI. The value of $R_{\mathrm{ct}}$ increases while the value of $C_{\mathrm{dl}}$ decreases with increasing KI concentration. It is obvious that the adsorption extent of iodide ions on the metal/solution interface affects the value of $C_{\mathrm{dl}}$. The interfacial capacitance in the presence of KI may be expressed as follows:

$C_{\mathrm{c}}=\theta C_{\mathrm{s}}+(1-\theta) C_{0}$

$u=\lambda \theta$

where $u=1-C_{c} / C_{0}, \lambda=1-C_{s} / C_{0} ; \theta$ is the surface coverage which can be evaluated from the expression: $\eta \%=\theta \times 100 ; C_{0}$ is the interfacial capacitance in the absence of $\mathrm{KI}$, and $C_{\mathrm{c}}$ is the interfacial capacitance in the presence of $\mathrm{KI}$; $C_{\mathrm{s}}$ is the interfacial capacitance when $\theta$ equals to 1 .

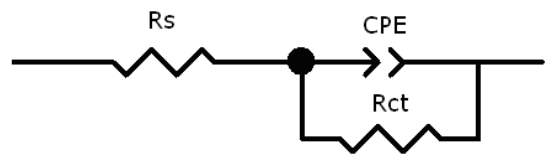

Fig. (2). Equivalent electrical circuit of the interface of mild steel / $\mathrm{HCl}$ solution both in the absence and presence of CBE or CBEK.

Plotting $u$ against $\theta$ gives a straight line, as shown in Fig. (3). Then $C_{\mathrm{s}}$ can be calculated from the slope. The obtained $C_{\mathrm{s}}$ was between 70 and $60 \mu \mathrm{F} \mathrm{cm}^{-2}$. The decrease in $C_{\mathrm{dl}}$ with increasing $\mathrm{KI}$ concentration indicates that the iodide ions adsorb on the metal/solution interface and replace $\mathrm{H}_{2} \mathrm{O}$ molecules. As shown in Table 2, the value of $C_{\mathrm{dl}}$ is less than $60 \mu \mathrm{F} \mathrm{cm} ~^{-2}$ in the coexistence of $\mathrm{KI}$ and $\mathrm{CBE}$, and the inhibition efficiency is higher in the coexistence system than that in the presence of $\mathrm{KI}$ or $\mathrm{CBE}$. This suggests that $\mathrm{CBE}$ molecules also replace $\mathrm{H}_{2} \mathrm{O}$ molecules and directly adsorb on the metal surface.

Fig. (4) shows the inhibition efficiencies of $\mathrm{CBE}$ and CBEK for Q235 mild steel after immerged in $1 \mathrm{M} \mathrm{HCl}$ solution for different times at $25^{\circ} \mathrm{C}$. The inhibition efficiency increases with the prolongation of immersion time for both inhibitors. The inhibition efficiency is higher in the presence of CBEK than that in the presence of CBE. Furthermore, compared to the inhibition efficiency of $\mathrm{CBE}$, it takes shorter time for the inhibition efficiency to reach a stable value in the coexistence of $\mathrm{KI}$ and $\mathrm{CBE}$, which may be due to the synergistic effect between $\mathrm{CBE}$ molecules and iodide anions.

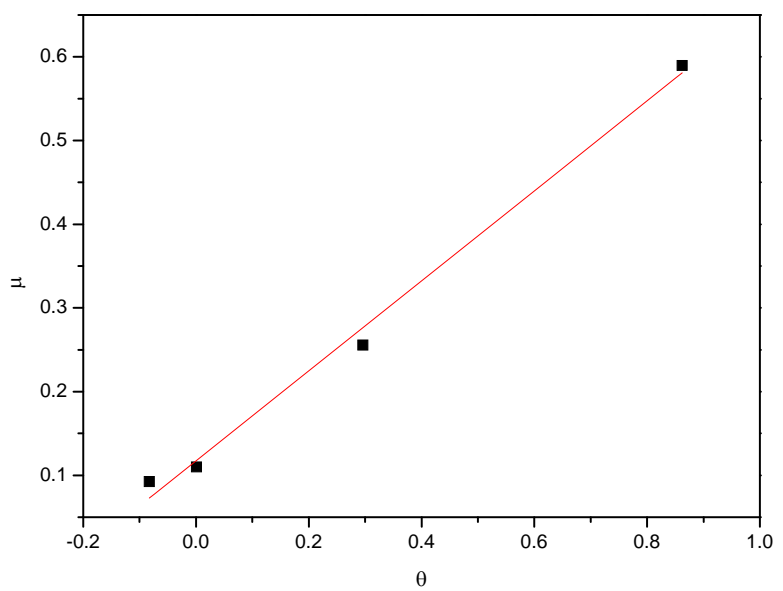

Fig. (3). A plot of u versus $\theta$ for the adsorption of iodide ions.

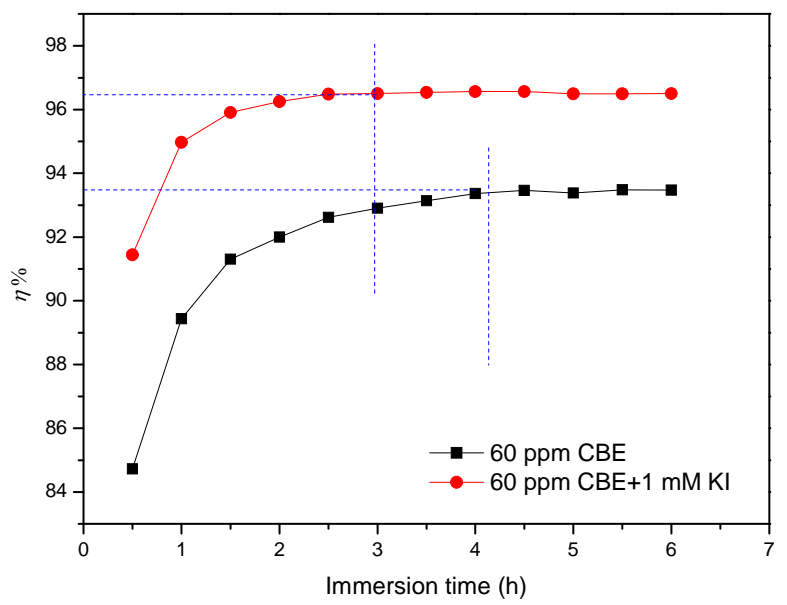

Fig. (4). Time dependence of the inhibition efficiencies of CBE and CBEK for Q235 mild steel in $1 \mathrm{M} \mathrm{HCl}$ solution at $25^{\circ} \mathrm{C}$. 


\section{POTENTIODYNAMIC POLARIZATION CURVES MEASUREMENTS}

Fig. (5) shows the polarization curves of Q235 mild steel in $1 \mathrm{M} \mathrm{HCl}$ solution in the presence of $\mathrm{CBE}$ and/or $\mathrm{KI}$ at $25^{\circ} \mathrm{C}$. It can be seen that the presence of $\mathrm{CBE}$ causes a decrease in both anodic and cathodic current densities. The anodic and cathodic current densities further decrease with adding $2.5 \mathrm{mM} \mathrm{KI}$ suggests that both $\mathrm{CBE}$ and $\mathrm{CBK}$ are mixed-type inhibitors. Furthermore, there is no significant change (less than $85 \mathrm{mV}$ ) in the corrosion potential in the presence of CBE and KI [18].

To assess the influence of temperature and inhibitor concentration on inhibition efficiency, potentiodynamic polarization curves measurements were carried out at $25^{\circ} \mathrm{C}$ and $35^{\circ} \mathrm{C}$ with different concentrations of CBE. The values of corresponding parameters for polarization curves, such as corrosion potential $\left(E_{\text {corr }}\right)$, corrosion current density $\left(i_{\text {corr }}\right)$, anodic and cathodic Tafel slope $\left(b_{\mathrm{a}}, b_{\mathrm{c}}\right)$ listed in Table $\mathbf{3}$, are obtained by fitting data measured in $\pm 80 \sim \pm 150 \mathrm{mV} v s$ $E_{\text {corr }}$ using professional software installed in the electrochemical test system. It is seen that the corrosion current density increases with the increase of temperature in both the uninhibited and inhibited solutions. However, the inhibition efficiency of $\mathrm{CBE}$ or CBEK increases with increasing temperature and concentration. Furthermore, inhibition efficiency of CBEK is higher than that of $\mathrm{CBE}$, as shown in Fig. (6), which indicates a synergistic effect of these two inhibitors.

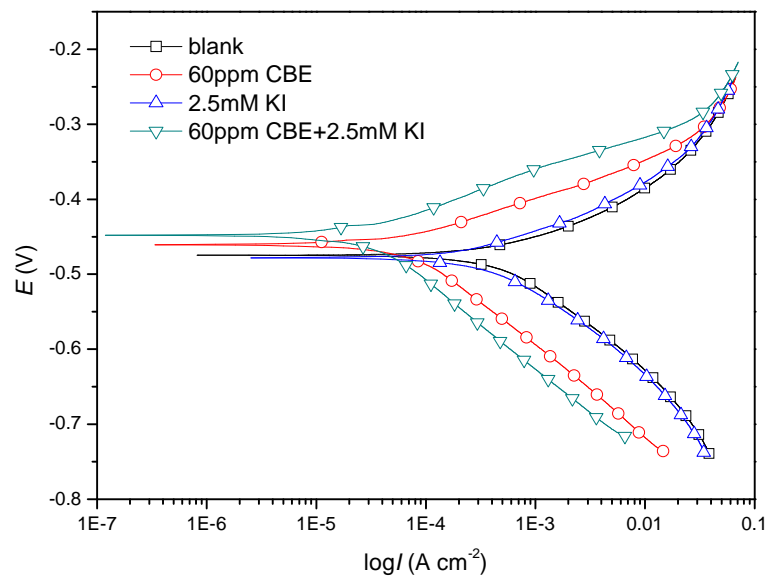

Fig. (5). Polarization curves of Q235 mild steel in $1 \mathrm{M} \mathrm{HCl}$ solution in the presence of $\mathrm{CBE}, \mathrm{KI}$ and $\mathrm{CBEK} 25^{\circ} \mathrm{C}$.

\section{ADSORPTION AND DESORPTION BEHAVIORS OF CBE AND CBEK}

It is acknowledged that the adsorption behavior of an inhibitor can be analyzed by the adsorption mechanism,

Table 3. Potentiodynamic polarization parameters for $\mathrm{Q} 235$ mild steel in $1 \mathrm{M} \mathrm{HCl}$ and in the presence of $\mathrm{CBE}$ or $\mathrm{CBEK}$ at $25^{\circ} \mathrm{C}$ and $35^{\circ} \mathrm{C}$.

\begin{tabular}{|c|c|c|c|c|c|c|c|c|}
\hline $\begin{array}{c}T \\
\left({ }^{\circ} \mathbf{C}\right)\end{array}$ & $\begin{array}{c}c_{\mathrm{CBE}} \\
(\mathbf{p p m})\end{array}$ & $\begin{array}{c}c_{\mathrm{KI}} \\
(\mathbf{m M})\end{array}$ & $\begin{array}{l}-E_{\text {corr }} \\
(\mathrm{mV})\end{array}$ & $\begin{array}{c}b_{\mathrm{a}} \\
(\mathrm{mV})\end{array}$ & $\begin{array}{l}-b_{c} \\
(m V)\end{array}$ & $\begin{array}{c}i_{\text {corr }} \\
\left(\mu \mathrm{A} \mathrm{c \textrm {cm } ^ { - 2 }}\right)\end{array}$ & $\begin{array}{c}\eta \\
(\%)\end{array}$ & $S_{\mathrm{I}}$ \\
\hline \multirow{8}{*}{25} & 0 & 0 & 493.1 & 70.9 & 100.4 & 441.2 & -- & -- \\
\hline & 0 & 2.5 & 486.9 & 66.6 & 100.0 & 364.3 & 17.44 & -- \\
\hline & 20 & 0 & 483.9 & 56.7 & 104.8 & 143.7 & 67.43 & -- \\
\hline & 40 & 0 & 483.0 & 53.6 & 107.5 & 103.9 & 76.44 & -- \\
\hline & 80 & 0 & 484.1 & 46.7 & 120.5 & 60.5 & 86.30 & -- \\
\hline & 20 & 2.5 & 480.5 & 45.5 & 104.6 & 57.2 & 87.03 & 2.07 \\
\hline & 40 & 2.5 & 468.5 & 49.8 & 124.9 & 37.4 & 91.52 & 2.29 \\
\hline & 60 & 2.5 & 471.1 & 59.1 & 121.6 & 31.5 & 92.85 & 1.32 \\
\hline \multirow{8}{*}{35} & 0 & 2.5 & 479.6 & 50.5 & 91.4 & 391.8 & 48.45 & -- \\
\hline & 20 & 0 & 481.5 & 41.2 & 104.2 & 234.5 & 69.14 & -- \\
\hline & 40 & 0 & 479.9 & 35.9 & 106.8 & 104.5 & 86.25 & -- \\
\hline & 60 & 0 & 476.4 & 41.5 & 119.0 & 68.5 & 90.99 & -- \\
\hline & 80 & 0 & 480.1 & 41.9 & 107.8 & 65.9 & 91.33 & -- \\
\hline & 20 & 2.5 & 471.6 & 48.9 & 106.9 & 59.9 & 92.11 & 2.02 \\
\hline & 40 & 2.5 & 464.8 & 59.6 & 113.5 & 44.4 & 94.16 & 1.21 \\
\hline & 60 & 2.5 & 459.0 & 60.9 & 118.7 & 41.8 & 94.50 & 0.84 \\
\hline
\end{tabular}


assuming a direct relationship between the inhibition efficiency $(\eta \%)$ and the coverage of inhibitor $(\theta)$. Fig. (7) shows a linear relationship of $c / \theta$ versus $c$ with a proximate slope of unity and a high regression correlation coefficient (0.99). This suggests that the adsorption of CBE and CBEK on steel surface follows the Langmuir isotherm [19], which may be expressed as follows:

$c / \theta=1 / K+c$

where $K$ is adsorption equilibrium constant $\left(\mathrm{L} \mathrm{mg}^{-1}\right)$.

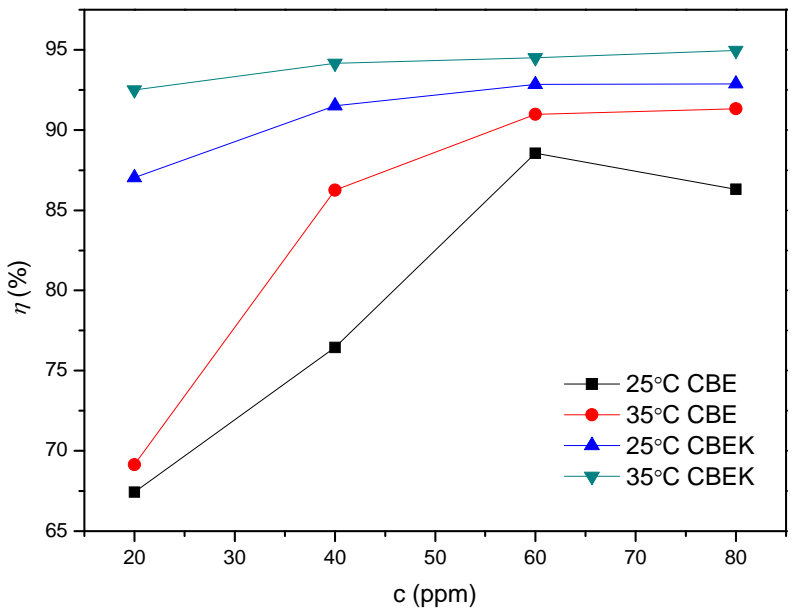

Fig. (6). Inhibition efficiencies of $\mathrm{CBE}$ or CBEK for Q235 mild steel in $1 \mathrm{M} \mathrm{HCl}$ solution at $25^{\circ} \mathrm{C}$ and $35^{\circ} \mathrm{C}$.

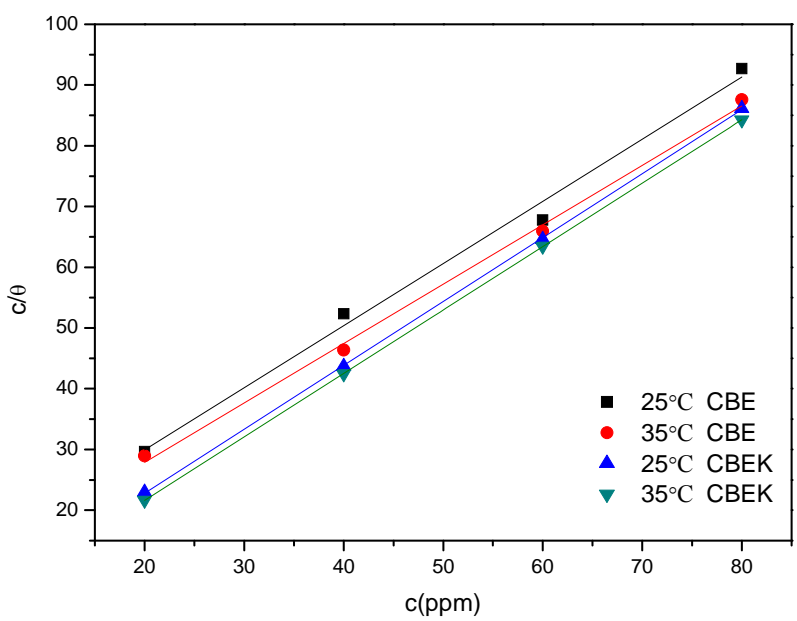

Fig. (7). Langmuir adsorption isotherm model for $\mathrm{CBE}$ and $\mathrm{CBEK}$ on Q235 mild steel surface.

To study the desorption behavior of CBEK inhibitor, differential polarization curve method was applied to the anodic polarization curve data [20].

$S=d \lg i / d E$

where $S$ is the reciprocal of the slope of every point on semilog polarization curve, and the $\mathrm{S}$ versus $\mathrm{E}$ is the differential polarization curve, as shown in Fig. (8). $E_{\text {des }}$ is the desorption potential and $E_{\mathrm{p}}$ is the potential corresponding to the peak of the inhibitor desorption [21]. It is observed that there are positive shifts in both the $E_{\text {des }}$ and $E_{\mathrm{p}}$ with increasing $\mathrm{CBE}$ concentration at each temperature. Furthermore, the value of $\mathrm{S}$ is higher at $35^{\circ} \mathrm{C}$ than that at 25 ${ }^{\circ} \mathrm{C}$ indicating that the desorption behavior of inhibitor is more prominent at $35{ }^{\circ} \mathrm{C}$ than that at $25{ }^{\circ} \mathrm{C}$. Fig. (9) shows a half logarithm relationship between $E_{\text {des }}$ and $\mathrm{CBE}$ concentration $(c)$, which probably suggests that the $\mathrm{CBE}$ concentration influence the value of $E_{\text {des, }}$ i.e., the $\mathrm{CBE}$ molecules can directly adsorb on the metal surface and then enhance the inhibition efficiency [20].
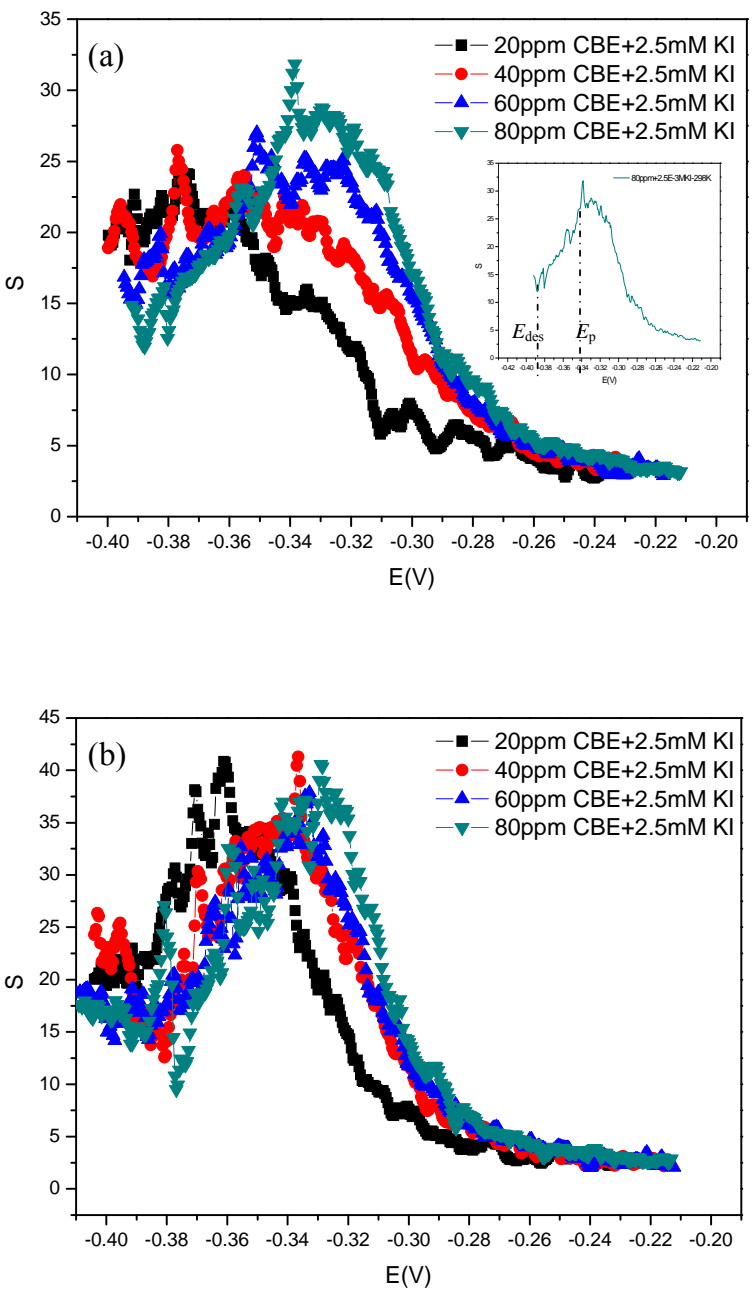

Fig. (8). The anodic differential polarization curve of Q235 mild steel in $1 \mathrm{M} \mathrm{HCl}$ solution in the presence of CBEK at (a) $25^{\circ} \mathrm{C}$, (b) $35^{\circ} \mathrm{C}$.

\section{THERMODYNAMIC AND KINETIC PARAMETERS}

It is well known that the inhibition efficiency and adsorption process of inhibitor can be evaluated by the thermodynamic and kinetic parameters. The equilibrium constant of adsorption is related to the standard free energy of adsorption, $\Delta G_{\text {ads }}$ by:

$$
K=\left\{\exp \left[\left(-\Delta G_{\text {ads }}\right) / R T\right]\right\} / c_{\text {solvent }}
$$

where $c_{\text {solvent }}$ represents the concentration of water in solution with the value of approximate $1.0 \times 10^{6}$, which results from the unit of $\mathrm{K}\left(\mathrm{L} \mathrm{mg}^{-1}\right)$ [22]. Table 4 lists the standard free 


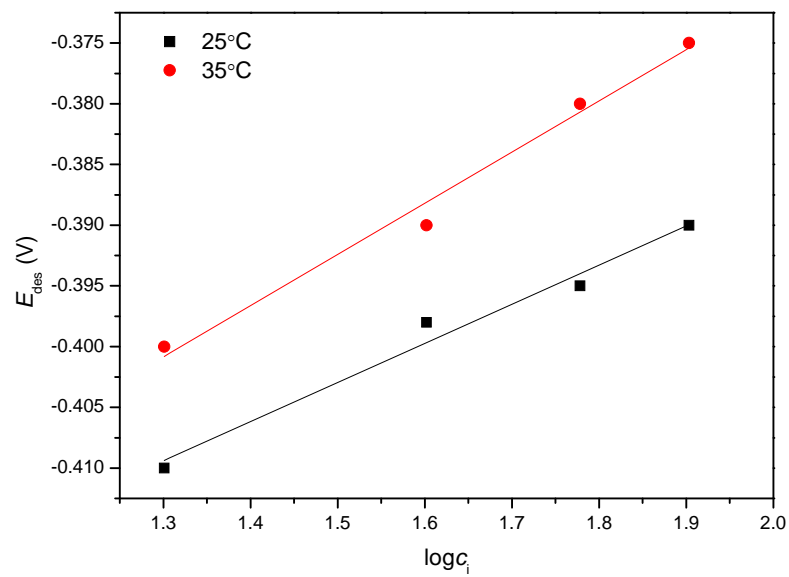

Fig. (9). The linear relationship between $E_{\text {des }}$ and $\mathrm{CBE}$ concentrations $\left(c_{\mathrm{i}}\right)$.

energy of adsorption ( $\Delta G_{\text {ads }}$ ) of CBE with and without KI at $25^{\circ} \mathrm{C}$ and $35^{\circ} \mathrm{C}$. It can be seen that both the $\Delta G_{\text {ads }}$ values in inhibited systems are negative, suggesting the spontaneity of the adsorption process and the stability of the adsorbed inhibitor layer on the steel surface. The variation trend of $\Delta G_{\text {ads }}$ values is associated with the inhibition efficiency, i.e., the value of $\Delta G_{\text {ads }}$ increases with temperature and a higher value in CBEK synergistic inhibited system compared to CBE alone inhibited system. Generally, $\Delta G_{\text {ads }}$ values more negative than $-40 \mathrm{~kJ} \mathrm{~mol}^{-1}$ involve charge sharing or transfer from the inhibitor molecules to the metal surface to form a coordinate type of bond (chemisorption), and $\Delta G_{\text {ads }}$ values of approximately $-20 \mathrm{~kJ} \mathrm{~mol}^{-1}$ or lower indicate the electrostatic attraction between the charged metal surface and the charged organic molecules in the solution [23]. Furthermore, a value of $\Delta G_{\mathrm{ads}}$ between $-20 \mathrm{~kJ} \mathrm{~mol}^{-1}$ and $-40 \mathrm{~kJ} \mathrm{~mol}^{-1}$ indicates two types of adsorption on the metal surface, i.e., physical adsorption and chemisorption. And chemisorption plays a more important role increasing with temperature.

Table 4. The free energy of adsorption ( $\Delta G_{\text {ads }}$ ) of CBE with and without $\mathrm{KI}$ at $25^{\circ} \mathrm{C}$ and $35^{\circ} \mathrm{C}$.

\begin{tabular}{|c|c|c|c|}
\hline $\boldsymbol{T}\left({ }^{\circ} \mathbf{C}\right)$ & $\boldsymbol{c}_{\mathrm{KI}}(\mathbf{m M})$ & $\boldsymbol{K}\left(\mathbf{L ~ m g}^{-1}\right)$ & $\boldsymbol{\Delta} \boldsymbol{G}_{\text {ads }}\left(\mathbf{k J ~} \mathbf{~ m o l}^{-1}\right)$ \\
\hline \hline 25 & 0 & 0.106 & -28.66 \\
\hline 35 & 0 & 0.120 & -29.96 \\
\hline 25 & 2.5 & 0.566 & -32.82 \\
\hline 35 & 2.5 & 1.341 & -36.13 \\
\hline
\end{tabular}

The values of apparent activation energy $\left(E_{\mathrm{a}}\right)$, heat of adsorption $\left(Q_{\mathrm{ads}}\right)$, can be calculated using the following equations $(9,10)[24]$ :

$i_{\text {corr }}=A \exp \left[\left(-E_{\mathrm{a}}\right) / R T\right]$

$Q_{\text {ads }}=2.303 R\left[\log \left(\frac{\theta_{2}}{1-\theta_{2}}\right)-\log \left(\frac{\theta_{1}}{1-\theta_{1}}\right)\right] \times\left(\frac{T_{1} \times T_{2}}{T_{2}-T_{1}}\right)$

where $\theta_{1}$ and $\theta_{2}$ are degree of surface coverage at temperature $T_{1}$ and $T_{2}$, respectively. Table 5 lists the values of $\triangle E_{\mathrm{a}}$ and $Q_{\mathrm{ads}}$ for the corrosion of Q235 mild steel in $1 \mathrm{M}$ $\mathrm{HCl}$ solution without and with $\mathrm{CBE}$ or CBEK between $25^{\circ} \mathrm{C}$ and $35^{\circ} \mathrm{C}$, respectively. It is found that the $E_{\mathrm{a}}$ value in the inhibited system is lower than that in the uninhibited system. The reduction of $E_{\mathrm{a}}$ in the presence of inhibitor may be attributed to the chemisorption of inhibitor on the steel surface [25-27]. With the increase of temperature, some chemical changes occur in the inhibitor molecules, leading to an increment in the electron densities at the adsorption centre of inhibitor molecules and then an improvement in inhibition efficiency. Moreover, the $E_{\mathrm{a}}$ in the coexistence of $\mathrm{CBE}$ and $\mathrm{KI}$ is much lower than that in the inhibited system of $\mathrm{CBE}$ alone. It is also seen that the $Q_{\text {ads }}$ values are positive in all the cases. The positive value of $Q_{\text {ads }}$ may suggest the presence of chemisorption adsorption [28]. The variation trend of $Q_{\mathrm{ads}}$ is associated with the inhibition efficiency, i.e., $Q_{\text {ads }}$ increases with temperature and a higher value in $\mathrm{CBE}$ and $\mathrm{KI}$ synergistic inhibited system compared to $\mathrm{CBE}$ alone inhibited system.

Table 5. Values of $E_{\mathrm{a}}\left(\mathrm{kJ} \mathrm{mol}^{-1}\right)$ and $Q_{\text {ads }}\left(\mathrm{kJ} \mathrm{mol}^{-1}\right)$ for $\mathrm{Q235}$ mild steel in $1 \mathrm{M}$ HCl solution without and with CBE or CBEK.

\begin{tabular}{|c|c|c|}
\hline Conditions & $\boldsymbol{E}_{\mathbf{a}}\left(\mathbf{k J ~ m o l}{ }^{\mathbf{1}}\right)$ & $\boldsymbol{Q}_{\text {ads }}\left(\mathbf{k J ~} \mathbf{~ m o l}^{\mathbf{1}}\right)$ \\
\hline \hline Blank & 41.99 & 0 \\
\hline CBE & 17.08 & 28.99 \\
\hline CBEK & 13.42 & 30.63 \\
\hline
\end{tabular}

\section{DISCUSSION}

Generally, for the interaction of inhibitors A and B, the synergism parameter $\left(S_{\mathrm{I}}\right)$ is defined as follows [29]:

$S_{\mathrm{I}}=\left(1-\eta_{\mathrm{A}}-\eta_{\mathrm{B}}+\eta_{\mathrm{A}} \eta_{\mathrm{B}}\right) /\left(1-\eta_{\mathrm{A}+\mathrm{B}}\right)$

where $\eta_{\mathrm{a}}$ and $\eta_{\mathrm{B}}$ are the inhibition efficiencies of inhibitors $\mathrm{A}$ and $\mathrm{B}$, respectively, and $\eta_{\mathrm{A}+\mathrm{B}}$ is the inhibition efficiency for the combination of inhibitors A and B. Generally, $S_{\mathrm{I}}$ approaches 1 when inhibitors A and B have no interaction on each other at the metal /solution interface, while $S>1$ indicates a synergistic effect. In the case of $S<1$, antagonistic effect prevails, which may be attributed to competitive adsorption. The calculated values of $S_{\text {I }}$ for different $\mathrm{CBE}$ concentrations with certain iodide ions concentration are listed in Table 3 . It is seen that the value of $S_{\text {I }}$ is more than unity and decreasing with rise in concentration at $25^{\circ} \mathrm{C}$, which suggests a synergistic effect between $\mathrm{CBE}$ and $\mathrm{KI}$, and the effect weakens at higher $\mathrm{CBE}$ concentration. And the variation of $S_{\mathrm{I}}$ at $35^{\circ} \mathrm{C}$ is the same with that at $25^{\circ} \mathrm{C}$. However, $S_{\text {I }}$ decreases to below unity when $\mathrm{CBE}$ concentration reaches $60 \mathrm{ppm}$ at $35^{\circ} \mathrm{C}$. This maybe due to the easier adsorption of CBE onto the steel surface when the concentration and temperature increasing.

In the absence of iodide ions, the inhibitive action of $\mathrm{CBE}$ is due to the composition of numerous organic compounds [30-32], which contain oxygen and nitrogen atoms in functional groups $(\mathrm{O}-\mathrm{H}, \mathrm{C}-\mathrm{N}, \mathrm{C}=\mathrm{C}, \mathrm{C}-\mathrm{O}-\mathrm{C})$ and an aromatic ring. These chemical compounds meet the general consideration of typical corrosion inhibitors [28], 
and may react with the ferrous ions, which result from the dissolution of steel (anodic reaction) [33], to form organometallic complex such as [Fe-CBE] to reduce hydrogen evolution reaction (cathodic reaction) according to the following mechanism [34]:

$$
\begin{aligned}
& \mathrm{Fe}_{M} \rightleftharpoons \mathrm{Fe}_{\text {sol }}^{2+}+2 e_{M} \\
& \mathrm{Fe}+\mathrm{CBE} \rightarrow[\mathrm{Fe}-\mathrm{CBE}]
\end{aligned}
$$

At the same time, it is well known that the steel surface charges positive charge in acid solution and most plant molecules can be protonated in the acid medium as follows:

$$
\mathrm{CBE}+x \mathrm{H}^{+} \rightarrow\left[\mathrm{CBEH}_{x}\right]^{x+}
$$

In this case, it would be difficult for the protonated CBE molecules to approach the positively charged steel surface because of electrostatic repulsion. However, in the presence of iodide ions, the anions are specifically adsorbed on the steel surface due to the smaller degree of hydration, which allows the protonated CBE molecules to easily approach the steel surface $[35,36]$. The protonated CBE may adsorb on the steel surface through iodide ions to form organo - iodide - metallic complex such as $\left[\mathrm{Fe}-\mathrm{I}-\mathrm{CBEH}_{\mathrm{x}}\right]^{\mathrm{x}-1}$ according to the following mechanism:

$$
\left[\mathrm{CBEH}_{x}\right]^{x+}+\mathrm{I}^{-}+\mathrm{Fe} \rightarrow\left[\mathrm{Fe}-\mathrm{I}-\mathrm{CBEH}_{x}\right]^{x-1}
$$

Thus, in the coexistence of $\mathrm{CBE}$ and iodide ions, two adsorption modes $[\mathrm{Fe}-\mathrm{CBE}]$, and $\left[\mathrm{Fe}-\mathrm{I}-\mathrm{CBEH}_{\mathrm{x}}\right]^{\mathrm{x}-1}$, should account for the synergistic inhibition effect. These complexes might adsorb on steel surface mainly through chemisorption, while electrostatic interaction and van der Waals force also play a role in forming a stable protective film, resulting in an inhibitive effect $[37,38]$.

\section{CONCLUSION}

Capsella bursa-pastoris extracts (CBE) can be used as an effective, eco-friendly inhibitor for mild steel in acid environment.

The inhibition efficiency is further enhanced in the coexistence of CBE and KI (CBEK), and it takes shorter time for the inhibition efficiency to reach a stable value in the presence of CBEK compared to CBE, which may be due to the synergistic effect between $\mathrm{CBE}$ molecules and iodide anions i.e., the protonated $\mathrm{CBE}$ adsorb on negatively charged metal surface after adsorbing iodide ions.

Both CBE and CBEK act as mix-type inhibitors. The inhibition efficiency increases with the concentration, temperature and immersion time. The differential polarization curves suggest that both the desorption potential $\left(E_{\mathrm{des}}\right)$ and the peak potential $\left(E_{\mathrm{p}}\right)$ shift positively with increasing $\mathrm{CBE}$ concentration and temperature, i.e., a more stable protective film at higher temperature and inhibitor concentration.

The adsorption of CBE and CBEK on metal surface obey Langmuir adsorption isotherm. The apparent activation energy $\left(E_{\mathrm{a}}\right)$ and heat of adsorption $\left(Q_{\mathrm{ads}}\right)$ are support the chemisorption process. While the free energy of adsorption $\left(\Delta G_{a d s}\right)$, support both the physical adsorption and chemisorption are spontaneous exist, and chemisorption plays a key role at higher temperature.

\section{CONFLICT OF INTEREST}

The authors confirm that this article content has no conflict of interest.

\section{ACKNOWLEDGEMENTS}

The authors acknowledge the support of the National Natural Science Foundation of China (Grant No. 51101066) and the Analytical and Testing Center of the Huazhong University of Science and Technology.

\section{REFERENCES}

[1] Al-Otaibia MS, Al-Mayoufa AM, Khana M, et al. Corrosion inhibitory action of some plant extracts on the corrosion of mild steel in acidic media. Arab J Chem doi:10.1016/j.arabjc.2012.01.015.

[2] Abboud Y, Abourriche A, Ainane T, Hammouti, et al. Corrosion inhibition of carbon steel in acid media by bifurcaria bifurcata extract. Chem Eng Commun 2009; 196: 788-800.

[3] Orubite KO, Oforka NC. Inhibition of the corrosion of mild steel in hydrochloric acid solutions by the extracts of leaves of Nypa fruticans Wurmb. Mater Lett 2004; 58: 1768-72.

[4] Okafor PC, Liu CB, Zhu YJ, Zheng YG. Corrosion and corrosion inhibition behavior of $\mathrm{N} 80$ and $\mathrm{P} 110$ carbon steels in $\mathrm{CO}_{2}$-saturated simulated formation water by rosin amide imidazoline. Ind Eng Chem Res 2011; 50: 7273-81.

[5] Satapathy AK, Gunasekaran G, Sahoo SC, Amit K, Rodrigues PV. Corrosion inhibition by Justicia gendarussa plant extract in hydrochloric acid solution. Corros Sci 2009; 51: 2848-56.

[6] Gece G. Drugs: A review of promising novel corrosion inhibitors. Corros Sci 2011; 53: 3873-98.

[7] Aramaki K, Hackerman N. Inhibition mechanism of medium-sized polymethyleneimine. J Electrochem Soc 1969; 116: 68-574.

[8] Ebenso EE. Synergistic effect of halide ions on the corrosion inhibition of aluminium in $\mathrm{H}_{2} \mathrm{SO}_{4}$ using 2-acetylphenothiazine. Mat Chem Phys 2003; 79: 58-70.

[9] Eduok UM, Umoren SA, Udoh AP. Synergistic inhibition effects between leaves and stem extracts of Sida acuta and iodide ion for mild steel corrosion in $1 \mathrm{M} \mathrm{H}_{2} \mathrm{SO}_{4}$ solutions. Arabi J Chem 2012; 5: 325-37.

[10] Tao P, Wang JB. Identification and characterization of transcripts differentially expressed during embryogenesis in Capsella bursapastoris. Biologia Plantarum 2012; 56: 415-21.

[11] Grosso C, Vinholes J, Silva LR, et al. Chemical composition and biological screening of Capsella bursa-pastoris. Rev Bras Farmacogn Braz J Pharmacogn 2011; 21: 635-44.

[12] Bekker A, Sorour K, Miller S. The use of cardioselective $\beta$ blockers in a patient with idiopathic hypertrophic subaortic stenosis and chronic obstructive pulmonary disease. J Clin Anes 2002; 14: 589-91.

[13] Ivanova D, Gerova D, Chervenkov T, Yankova T. Polyphenols and antioxidant capacity of Bulgarian medicinal plants. J Ethnopharm 2005; 96: 145-50.

[14] Szauer T, Brandt A. Adsorption of oleates of various amines on iron in acidic solution. Electrochimica Acta 1981; 26: 1253-6.

[15] Bastos AC, Ferreira MGS, Simões AMP. Effects of mechanical forming on the corrosion of electrogalvanised steel. Corros Sci 2013; 69: 87-96.

[16] Orazem ME, Tribollet B. Electrochemical Impedance Spectroscopy. New Jersey: John Wiley \& Sons, Inc. 2008; pp. 236: the equation 13.9.

[17] Brug GJ, Van den Eeden ALG, Sluyters-Rehbach M, Sluyters JH. The analysis of electrode impedances complicated by the presence of a constant phase element. J Electroanal Chem 1984; 176: 27595.

[18] Yan Y, Li W, Cai L, Hou B. Electrochemical and quantum chemical study of purines as corrosion inhibitors for mild steel in $1 \mathrm{M} \mathrm{HCl}$ solution. Electrochimica Acta 2008; 53: 5953-60.

[19] Mallaiya K, Subramaniam R, Srikandan SS, et al. Electrochemical characterization of the protective film formed by the unsymmetrical Schiff's base on the mild steel surface in acid media. Electrochimica Acta 2011; 56: 3857-63.

[20] Wang DH, Bu XZ, Gan FX, Zou JY, Yao LA. A differential polarization curve method and its application in anodic desorption 
study of corrosion inhibitor. Corros Sci Protect Technol 1999; 01: 32-6.

[21] Drazic DM, Drazic VJ, Jevtic V. The slow adsorption of halide ions and some organics and their influence on corrosion rate determination from polarization data. Electrochimica Acta 1989; 34: 1251-7.

[22] Li XH, Deng SD. Inhibition effect of Dendrocalamus brandisii leaves extract on aluminum in $\mathrm{HCl}, \mathrm{H}_{3} \mathrm{PO}_{4}$ solutions. Corros Sci 2012; 65: 299-308.

[23] Yurt A, Ulutas S, Dal H. Electrochemical and theoretical investigation on the corrosion of aluminium in acidic solution containing some Schiff bases. App Sur Sci 2006; 253: 919-25.

[24] Oguzie EE, Onuchukwu AI, Okafor PC, Ebenso EE. Corrosion inhibition and adsorption behaviour of Ocimum basilicum extract on aluminium. Pigm Resin Technol 2006; 35: 63-70.

[25] Bentiss F, Traisnel M, Gengembre L, Lagrenée M. A new triazole derivative as inhibitor of the acid corrosion of mild steel: electrochemical studies, weight loss determination, SEM and XPS. App Sur Sci 1999; 152: 237-49.

[26] Okafor PC, Liu CB, Zhu YJ, Zheng YG. Corrosion and corrosion inhibition behavior of $\mathrm{N} 80$ and $\mathrm{P} 110$ carbon steels in $\mathrm{CO}_{2}$-saturated simulated formation water by rosin amide imidazoline. Ind Eng Chem Res 2011; 50: 7273-81.

[27] Lagrenee M, Mernari B, Bouanis M, Traisnel M, Bentiss F. Study of the mechanism and inhibiting efficiency of 3,5-bis(4-methylthiophenyl)-4H-1,2,4-triazole on mild steel corrosion in acidic media. Corros Sci 2002; 44: 573-88.

[28] Oguzie EE. Evaluation of the inhibitive effect of some plant extracts on the acid corrosion of mild steel. Corros Sci 2008; 50: 2993-8.
[29] Murakawa T, Nagaura S. Coverage of iron surface by organic compounds and anions in acid solutions. Corros Sci 1967; 7: 79-89.

[30] Grosso C, Vinholes J, Silva LR, et al. Chemical composition and biological screening of Capsella bursa-pastoris. Rev Bras Farmacogn Braz J Pharmacogn 2011; 21: 635-44.

[31] Wei X. Studies on the chemical constituents of domestic-made Capsella bursa-pastoris (L.); Master diss., Dept. of medic. Shenyang Pharmaceutical University 2007.

[32] Liu JP. The characteristics and high yield plant technology of Capsella bursa-pastoris. Mod Agr Sci Tech 2010; 10: 126.

[33] De Souza FS, Spinelli A. Caffeic acid as a green corrosion inhibitor for mild steel. Corros Sci 2009; 51: 642-9.

[34] Gunasekaran G, Chauhan LR. Eco friendly inhibitor for corrosion inhibition of mild steel in phosphoric acid medium. Electrochimica Acta 2004; 49: 4387-95.

[35] EL-Gaber AS, Fouda AS, EI Desoky AM. Synergistic inhibition of zinc corrosion by some anions in aqueous media. Ciência Tecnologia dos Materials 2008; 20: 71-7.

[36] Musa AY, Mohamad AB, Kadhum AAH, Takriff MS, Tien LT. Synergistic effect of potassium iodide with phthalazone on the corrosion inhibition of mild steel in 1.0 M HCl. Corros Sci 2011; 53: 3672-7.

[37] Bentiss F, Traisnel M, Lagrenee M. The substituted 1, 3, 4oxadiazoles: a new class of corrosion inhibitors of mild steel in acidic media. Corros Sci 2000; 42: 127-46.

[38] Mayakrishnan G, Pitchai S, Raman K, Vincent AR, Nagarajan S. Inhibitive action of Clematis gouriana extract on the corrosion of mild steel in acidic medium. Ionics 2011; 17: 843-52.

(C) Hu et al.; Licensee Bentham Open.

This is an open access article licensed under the terms of the Creative Commons Attribution Non-Commercial License (http://creativecommons.org/licenses/by-nc/3.0/) which permits unrestricted, non-commercial use, distribution and reproduction in any medium, provided the work is properly cited. 